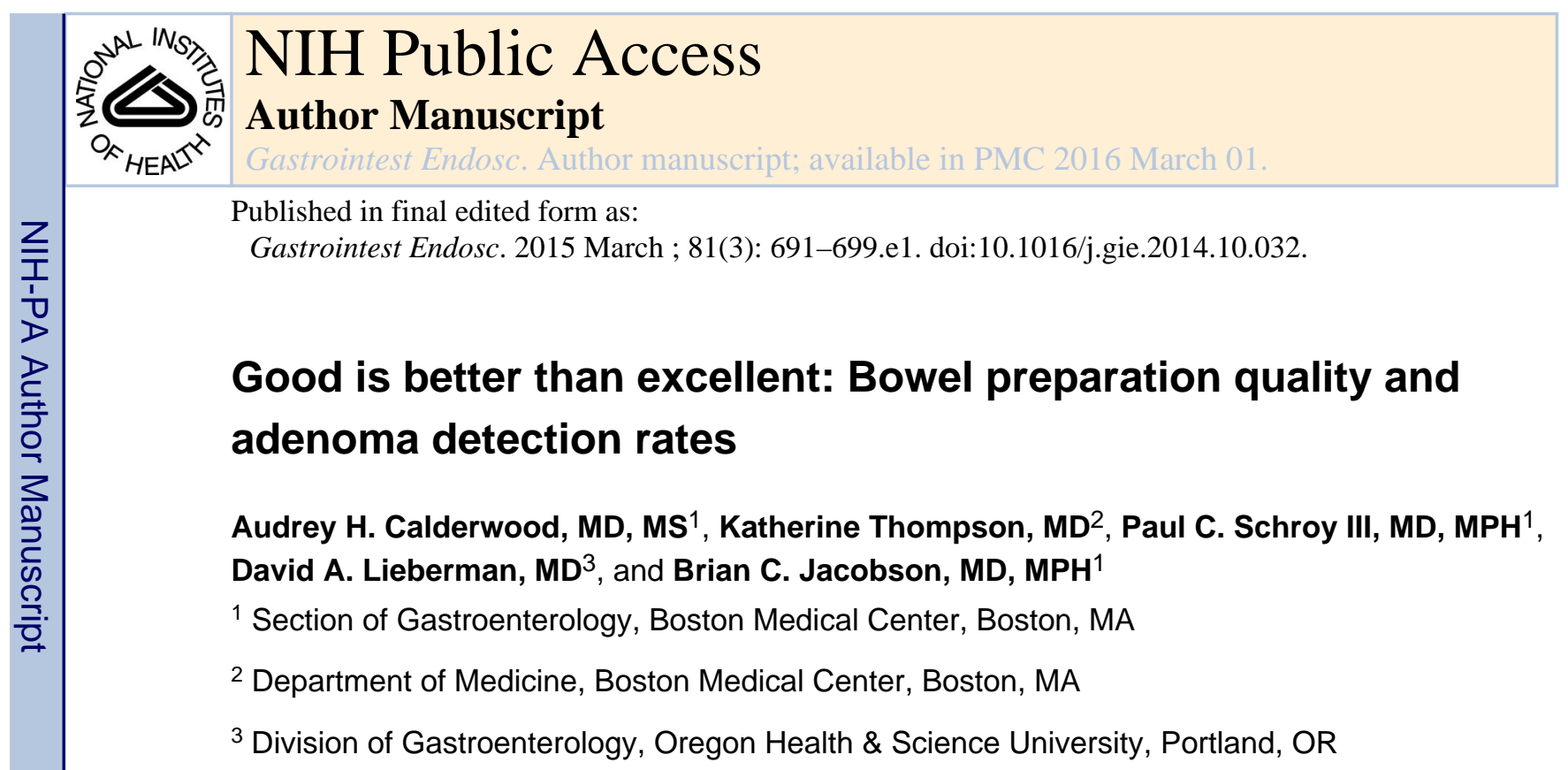

\title{
Abstract
}

Background-Inadequate bowel cleanliness is associated with missed lesions, yet whether polyp and adenoma detection rates (PDR, ADR) increase at the highest levels of bowel cleanliness is unknown.

Objective-To evaluate the association between bowel preparation quality using the Boston Bowel Preparation Scale (BBPS) and PDR and ADR among colonoscopies with adequate preparation.

Design-Cross-sectional analysis

Setting-Boston Medical Center (BMC) and the Clinical Outcomes Research Initiative (CORI)

Patients-Average-risk ambulatory patients attending screening colonoscopy with adequate bowel preparation defined as BBPS score $\geq 6$

Main Outcome Measurements-PDR and ADR stratified by BBPS score

Results-Among the 3713 colonoscopies at BMC performed by 19 endoscopists, the PDR, ADR, and advanced ADR were 49.8\%, 37.7\%, and 6.0\%, respectively. Among the 5532

(C) 2014 by the American Society for Gastrointestinal Endoscopy. All rights reserved

Corresponding author: Audrey H. Calderwood, MD, MS, 85 East Concord Street, Room 7724, Boston, MA 02118, T: (617) 638-8211, F: (617) 638-6529, Audrey.calderwood@bmc.org.

Author contributions: Calderwood (study concept and design, analysis and interpretation of data, drafting of manuscript, critical revision, obtaining funding); Thompson (acquisition of data, analysis and interpretation of data, critical revision); Schroy (analysis and interpretation of data, critical revision); Lieberman (acquisition of data, analysis and interpretation of data, critical revision), Jacobson (study concept and design, analysis and interpretation of data, critical revision, study supervision). All authors gave final approval of the manuscript.

Publisher's Disclaimer: This is a PDF file of an unedited manuscript that has been accepted for publication. As a service to our customers we are providing this early version of the manuscript. The manuscript will undergo copyediting, typesetting, and review of the resulting proof before it is published in its final citable form. Please note that during the production process errors may be discovered which could affect the content, and all legal disclaimers that apply to the journal pertain.

Conflicts of Interests: D. Lieberman is the executive director of the Clinical Outcomes Research Initiative (CORI), a nonprofit organization supporting this study. This potential conflict of interest has been reviewed and managed by the Oregon Health \& Science University and Veterans Affairs Conflict of Interest in Research Committee. Brian Jacobson serves as a consultant to Olympus and Motus GI. The remaining authors have no conflicts of interest to disclose.

Presented in part at Digestive Disease Week May 6, 2014 in Chicago, IL. 
colonoscopies in CORI performed by 85 endoscopists at 41 different sites, the PDR was $44.5 \%$ and PDR for polyps $>9 \mathrm{~mm}$ (surrogate for advanced ADR) was $6.2 \%$. The PDR associated with total BBPS scores of 6,7 , and 8 were higher than those associated with a BBPS score of 9 at BMC (BBPS 6:51\%, BBPS 7:53\%, BBPS 8:52\% vs. BBBPS 9:46\%; $\mathrm{P}=.002$ ) and CORI (BBPS 6:51\%, BBPS 7:48\%, BBPS 8:45\% vs. BBPS 9:40\%; $\mathrm{P}<.0001$ ). This trend persisted after adjusting for age, gender, race/ethnicity and was also observed for ADR and advanced ADR. PDR was higher among "good" compared to "excellent" preparations at BMC (OR 1.3 [1.0-1.5]) and CORI (OR $4.7[3.1-7.1])$.

\section{Limitations-Retrospective study}

Conclusions-The PDR and ADR decreased at the highest levels of bowel cleanliness.

Endoscopists finding a pristine bowel preparation should avoid a sense of over-confidence for polyp detection during the inspection phase of screening colonoscopy and still perform a careful evaluation for polyps. Furthermore, endoscopists expending additional effort to maximize cleansing of the bowel should never sacrifice on their inspection technique or inspection time.

\section{Keywords}

colonoscopy; adenoma detection; bowel preparation

\section{Introduction and background}

The effectiveness of colonoscopy, including its ability to diagnose precancerous lesions and prevent colorectal cancer, is dependent on the cleanliness of the bowel. Inadequate bowel cleanliness is associated with prolonged procedure times, the need for repeat procedures at accelerated intervals, increased costs and adverse events, and an estimated overall adenoma miss rate of $35 \%$ to $42 \% .1-5$ Despite the importance of bowel cleanliness, up to $25 \%$ of colonoscopies remain inadequately prepared.1,2,6

It seems logical then that improving bowel cleanliness would yield higher adenoma detection rates. A few recent studies, however, have found that "fair" preparations may have similar, rather than lower, adenoma detection rates compared to "adequate" or "optimal" preparations.7,8 Furthermore, among several studies focused on quality metrics for colonoscopy, polyp or adenoma detection rates appeared to be slightly lower, rather than higher, for "excellent" preparations compared to "good." $1,8-11$ We were interested in exploring whether this decrement in polyp and adenoma detection rates at the highest levels of bowel cleanliness was reproducible, given its implications for the level of care endoscopists use while inspecting for polyps even when the colon is very clean. Furthermore, we were interested in whether this relationship would persist when using the Boston Bowel Preparation Scale (BBPS), a valid and reliable tool which provides a more granular evaluation of bowel cleanliness and has the ability to preserve differences in bowel preparation quality among different segments of the colon.12,13 We therefore evaluated the association between bowel preparation quality and polyp and adenoma detection rates among colonoscopic examinations in 2 distinct large patient cohorts. 


\section{Methods}

This study was approved by the Institutional Review Boards at Boston Medical Center (IRB \#H-32416) in October 2013 and Oregon Health \& Science University (eIRB \#7038) in February 2011 with waivers of informed consent. This study used a limited dataset and was therefore exempted from further IRB review.

\section{Study sample}

We performed a cross-sectional analysis of ambulatory average-risk screening colonoscopies with adequate bowel preparation cleanliness documented using the Boston Bowel Preparation Scale (BBPS) at Boston Medical Center (BMC) and the Clinical Outcomes Research Initiative (CORI). Because of prior work showing that a total BBPS score $\geq 6$ corresponds to an adequate preparation, 14 we limited our study sample to averagerisk screening colonoscopies with total BBPS $₫$.

\section{Boston Medical Center}

BMC is a not-for-profit, urban, academic medical center affiliated with the Boston University School of Medicine. It is the largest safety-net hospital in New England and is affiliated with a large network of community health centers around Boston. Approximately $70 \%$ of BMC's patients are from racial and ethnic minority groups. Data were prospectively collected from May 2012 (when the BBPS was incorporated into the endoscopic report generator) to October 2013. Eligible patients were identified from BMC's computerized endoscopic report generator database (Provation ${ }^{\circledR} \mathrm{MD}$, Wolters Kluwer Health, Minneapolis, MN). Patient information including demographics was ascertained from the electronic medical record.

\section{The Clinical Outcomes Research Initiative}

CORI is a consortium of 61 adult gastrointestinal practices, including approximately 500 physicians in 18 states, which uses a structured computerized report generator to produce endoscopic reports. After quality control checks, reports from all sites are transmitted electronically to a central data repository for analysis. Data for this study was prospectively generated between October 2009 (when the BBPS was incorporated into CORI) and May 2013. Practice sites contributing colonoscopy reports during the study period included private practice (73\%), academic medical centers (9\%), and Department of Veterans Affairs (VA) hospitals (18\%).

\section{Selection criteria}

Average-risk ambulatory screening colonoscopy examinations with adequate bowel cleanliness as defined by a BBPS score of $\geq 6$ were included. Patients with inflammatory bowel disease, history of colonic resection or prior removal of polyps or cancer, or family history of colon neoplasia (i.e. adenomas or cancer) were excluded. Diagnostic and incomplete examinations unrelated to bowel preparation (e.g. technically difficulty or patient intolerance) and examinations in hospitalized patients were excluded. 


\section{Variables}

The number, size, and location of all polyps were included. For BMC data, pathology reports were used to determine the presence of adenomas and advanced adenomas (defined as any adenoma $\geq 10 \mathrm{~mm}$ in size, with villous features, high grade dysplasia, or invasive cancer), and serrated polyps. Because pathology was not available for CORI data, polyps $>9$ $\mathrm{mm}$ were considered a surrogate end point for advanced adenomas, an assumption that has been validated in CORI with $84 \%$ specificity. 15 Polyp location was defined as right colon (cecum and ascending colon), transverse colon (hepatic flexure, transverse colon, and splenic flexure), or left colon (descending colon, sigmoid colon, and rectum). We also collected the qualitative evaluation of the bowel cleanliness (i.e. "excellent", "good", or "fair") which was available in a subset of the examinations.

Variables associated with both bowel cleanliness and the incidence of polyps and adenomas were included in order to account for potential confounding on the relationship between bowel cleanliness and polyp or adenoma detection.13,16-21 Age,16-18 gender,13,16,19 self-reported race/ethnicity,13 diabetes mellitus (DM),18 and body mass index (BMI)20,21 were ascertained from the electronic medical record at BMC. In the CORI data, only age and gender were available due to the nature of the repository.

\section{Outcomes}

Our primary outcome was polyp detection rate (PDR) stratified by bowel cleanliness using total BBPS scores. Secondary outcomes included adenoma detection rate (ADR), advanced adenoma detection rate (advanced ADR), and serrated polyp detection rate as well as polyp detection rates stratified by other measures of bowel cleanliness including the qualitative assessment ("excellent", "good", "fair") and BBPS segment scores.

\section{Analysis}

Polyp detection rate was calculated as the number of examinations with at least 1 polyp divided by the total number of examinations. Similarly, ADR and advanced ADR were calculated as the number of examinations with at least 1 adenoma or advanced adenoma divided by the total number of examinations. We stratified PDR and ADR by total BBPS scores $(9,8,7,6)$ and BBPS segment scores $(3,2)$. For the segmental analysis, each examination contributed three segments for analysis (right, transverse, and left). Examinations in which polyp location was not specified were included in the analysis of total BBPS scores but not the segment analysis. Among the subset of examinations that also included a qualitative assessment of bowel cleanliness, we stratified PDR and ADR by "excellent," "good," and "fair."

We compared frequencies by using the chi square test. We calculated the odds ratio (OR) (95\% confidence intervals [CI]) of having a polyp or adenoma based on BBPS total and segment scores and qualitative descriptors using logistic regression. Characteristics associated with both PDR and bowel cleanliness were then included in multivariate logistic regression models to determine adjusted odds ratios (aOR) (95\% CI). For BMC data, this included age, gender, and race/ethnicity. For CORI data, this included age and gender; race/ 
ethnicity was not available. All statistical calculations were performed using SAS ${ }^{\circledR}$ Version 9.3 (Cary, NC). Significance was defined as a 2-tailed $P$ value $<0.05$.

\section{Sample size calculation}

We used all the data available at the time of analysis. We performed a post-hoc power calculation to determine that we had adequate power to have detected at least a 7\% difference in polyp detection rates. Assuming there was a significant difference in polyp detection rate between examinations with BBPS $9(50 \%)$ and examinations BBPS 8 (43\%), we would need 796 examinations with BBPS 9 and 796 examinations with BBPS 8 to have at least $80 \%$ power to detect a difference at the $P<0.05$ level.

\section{Results}

There were 3713 colonoscopies at BMC performed by 19 endoscopists that met inclusion criteria. In this cohort, $53.9 \%$ were female with a median age of 55 (interquartile range 51-62) years. Forty nine percent of examinations contained a qualitative assessment of the bowel cleanliness. Table 1 shows the distribution of BBPS scores and qualitative ratings, race/ethnicity data, prevalence of DM and BMI within the cohorts. The overall PDR, ADR, advanced ADR, and serrated PDR were 49.8\%, 37.7\%, 6.0\%, and 3.6\%, respectively. There were 5532 colonoscopies in CORI performed by 85 endoscopists at 41 different sites that met inclusion criteria. In this cohort, $50.4 \%$ were female with a median age of 58 (interquartile range 52-65) years. Only $19.2 \%$ of examinations also contained a qualitative assessment of bowel cleanliness. The overall PDR was $44.5 \%$ and PDR for polyps $>9 \mathrm{~mm}$ (surrogate for advanced ADR) was 6.2\%.

For the BMC cohort, we evaluated the association between potential covariates (age, gender, race/ethnicity, DM and BMI) and the independent (bowel cleanliness) and dependent (ADR, PDR) variables (Appendix 1). For the CORI cohort, we evaluated the association between the available potential covariates (age and gender) and the independent (bowel cleanliness) and dependent (PDR) variables. In both cohorts, older patients and males were more likely to have worse bowel preparation cleanliness and more polyps. At BMC, race/ethnicity was associated with both bowel cleanliness and polyp detection, however DM was only associated with bowel cleanliness and BMI was not associated with either. Therefore, we adjusted for age, gender, and race/ethnicity where available in the multivariable analyses.

Table 2 shows that the PDR, ADR, and advanced ADR associated with total BBPS scores of 6,7 , and 8 were higher than those associated with a BBPS score of 9. This finding persisted even after adjusting for age, gender, and race/ethnicity. This trend was not seen for polyps > $9 \mathrm{~mm}$ within CORI, although examinations with BBPS of 6 were more likely to have polyps in both unadjusted and adjusted analyses when compared to examinations with BBPS of 9 (OR 1.7[1.3-2.2] and aOR 1.6 [1.2-2.0]). At BMC, the rate of detection of serrated polyps was lowest in cases with BBPS scores of 9, however this was not statistically significant compared to other scores (BBPS 6: 4.1\% versus BBPS 7: $3.5 \%$ versus BBPS 8: $3.7 \%$ versus BBPS 9: $3.4 \%$; $>$ > 0.44). 
Among the subset of colonoscopies within CORI that also included a qualitative assessment of bowel cleanliness, PDR was higher among cases with "fair" (OR 2.0 [1.5-2.6]) and "good" (OR 4.7 [3.1-7.1]) preparations compared to "excellent" preparations and remained significant in the adjusted model (Table 3). For polyps $>9 \mathrm{~mm}$, "good" preparations (15.2\%) had higher polyp detection rates compared to "excellent" preparations (3.2\%) (OR 5.4 [2.8-10.5] and aOR 3.8 [1.9-7.6]). The same trend was seen among the BMC examinations, where "good" preparations were more likely than "excellent" preparations to have an adenoma (OR 1.3 [1.1-1.6]), however this was not statistically significant after adjusting for age, gender, and race/ethnicity (aOR 1.2 [0.94-1.4]).

In terms of segment scores, there were 6922 segments with a score of 3 and 4189 segments with a score of 2 at BMC and 6471 segments with a score of 3 and 9921 segments with a score of 2 in CORI. Both PDR and ADR were higher when BBPS segment scores were 2 compared to BBPS segment scores of 3 (Table 4). In the BMC data, the ADR was $18.2 \%$ in colon segments with a score of 2 compared to $15.5 \%$ in colon segments with a score 3 (OR1.2 [1.1-1.3] and aOR 1.2 [1.0-1.3]). In the CORI data, the PDR was $21.2 \%$ in colon segments with a score of 2 compared to $18.3 \%$ in colon segments with a score of 3 (OR 1.2[1.1-1.3] and aOR 1.2 [1.1-1.2]). The higher PDR and ADR associated with segment scores of 2 compared to 3 was observed across all colon segments (right, transverse, and left). This trend was not statistically significant among advanced adenomas or polyps $>9$ $\mathrm{mm}$.

\section{Discussion}

In this study using 2 large independent cohorts of average-risk screening colonoscopy examintions with adequate bowel preparation, there was a slight decrease in PDR and ADR as the degree of bowel cleanliness improved from good to excellent. Although the absolute difference in detection rates is of uncertain clinical significance, it is important to note that we did not observe any marginal increase in PDR or ADR that might be expected as bowel cleanliness improved. This phenomenon persisted across all methods of bowel quality assessment including BBPS total scores (9 versus 8, 7, or 6), BBPS segment scores (3 versus 2) and qualitative descriptors ("excellent" versus "good"). The effect of preparation quality on ADR and PDR did not differ by location within the colon. We interpret our findings to suggest that even at the highest levels of bowel cleanliness, endoscopists should remain vigilant in their inspection of the colonic mucosa for polyps. Although we were likely underpowered to detect differences in serrated polyps among different BBPS scores, we did not observe an increase in detection at BBPS 9 compared to lower scores, suggesting that an excellent preparation may not be required for improved detection of serrated polyps either. Interestingly, there were some differences in the magnitude of effect size of bowel cleanliness on PDR and ADR when comparing examinations at BMC to CORI which may be due to the absence of histologic assessment in CORI when classifying polyps. In addition, there appeared to be a larger difference in PDR when comparing examinations with "good" to "excellent" in CORI compared to BMC, suggesting perhaps that qualitative ratings may not be uniformly applied across different practice settings. Of note, BBPS segment scores were applied more uniformly across sites, suggesting the BBPS may be a more standardized way to determine bowel preparation adequacy. 
To our knowledge, this is the first study to compare the PDR and ADR at the highest degrees of bowel cleanliness as a primary study aim. Prior studies designed to evaluate overall quality metrics in colonoscopy reported findings similar to ours, supporting the generalizability of our results.1,9,10 In an observational study of 15 hospitals in Spain nested within a larger randomized trial comparing screening colonoscopy and fecal immunohistochemical testing, ADR was higher in the setting of good (32.1\%) versus excellent (30.3\%) bowel preparations.10 That study used the Aronchick scale, which has been partially validated.22 A study with a large network of Italian endoscopy centers designed to identify factors associated with cecal intubation and polyp detection found that cases with good bowel preparations had a higher PDR than cases with excellent bowel preparations (28.2\% versus $27.4 \%$ ), but the difference was not significant (OR 1.02 [0.93-1.1]).9 That study included all colonoscopy examinations regardless of indication and as such, PDR may be lower than expected for a screening cohort such as ours. A limitation of that study was the lack of a validated bowel preparation rating system. In another large, prospective multicenter study evaluating the technical performance of endoscopy throughout Europe, examinations with the highest preparation quality had lower PDRs than examinations with intermediate preparation scores (29.4\% versus $32.8 \%) .1$ That study also included colonoscopies performed for all indications. Interestingly, the authors used a 5point scale ( $1=$ solid stool to $5=$ completely clean) and categorized the scores into three levels: "low" (scores of 1-2), "intermediate" (scores of 3), and "high" (scores of 4-5). That scale was neither validated nor tested for reliability.

The decrement in ADR and PDR at the highest levels of cleanliness merits further consideration. Why might this phenomenon occur? One possibility is that residual stool debris and/or a mucus cap may help highlight flat polyps.23,24 Another possible explanation is that the cleaning process itself may distract endoscopists from inspecting for polyps, such that time spent cleaning is time not spent looking. Thus, during an exam that is improved from an initial BBPS of 6 to 9, the endoscopist may be focused more on the cleaning process itself rather than inspecting for polyps. Alternatively, the presence of polyps may influence the endoscopists' assessment of bowel preparation quality such that when endoscopists do not find a polyp, they may unknowingly rate the preparation as cleaner than when they find a polyp. Last, encountering an excellent preparation may provide a false sense of confidence to endoscopists who might then experience a decrement in the quality of their inspection because of the assumption that they would find polyps easily within a pristine bowel.

Our study has several strengths. We included a large number of examinations from 2 distinct datasets, including 1 with a racially diverse population and another with a wide range of practice settings and locations throughout the United States. The use of the validated BBPS strengthens our findings as well because it provides a granular and reliable evaluation of the bowel cleanliness that also captures variation in cleanliness among the different colon segments. Last, we validated our findings by assessing the same outcomes using a different method of assessing bowel cleanliness, specifically qualitative descriptors, and found the same results. 
Despite these strengths, we acknowledge certain limitations. The absolute reduction in PDR and ADR at the highest levels of bowel cleanliness is small. However, we observed a 4-6\% greater ADR and a 2-3\% greater advanced ADR with less-than-perfect bowel preparations compared to the highest categories of cleanliness and consider this a clinically meaningful difference. Similarly small differences in endoscopist ADRs have been significantly associated with the risk of interval colorectal cancers.25,26 There was also no substantial or significant increase in PDR or ADR at the highest levels of bowel cleanliness again supporting the idea that a pristine prep may not improve outcomes and that endoscopists must remain vigilant in their inspection of the colonic mucosa regardless of the bowel cleanliness. Because these colonoscopy examinations were part of routine clinical care, we do not have information on the baseline bowel cleanliness before cleaning and therefore are unable to evaluate what role the improvement in bowel cleanliness during the examinations may have played. In other words, we cannot compare ADRs between colonoscopies whose initial and final bowel cleanliness were both classified as a BBPS $=9$ compared to colonoscopies whose bowel cleanliness was improved from an initial lower BBPS to a final BBPS $=9$, which would help evaluate the effect of fatigue and the act of cleaning distracting from efforts of inspection. We do not have information on withdrawal times. However, the medical literature has shown that withdrawal time alone is not necessarily a robust quality indicator27-30 and may not be associated with PDR in examinations with excellent bowel preparation quality.31 Even if we had information on withdrawal time, we would not know how the time was spent (e.g. looking vs. cleaning vs. performing an intervention) and as such, knowing withdrawal times may not be very informative. Importantly, we have shown in 2 separate settings now that PDR and ADR are mildly reduced in examinations with a BBPS 9 compared with those with a BBPS 6-8, supporting the cautionary message that endoscopists must remain vigilant in evaluating for polyps even during examinations that are pristine. We cannot account for individual endoscopist behavior with metrics such as individual ADR. Last, the lack of pathology in CORI limits our analysis of ADR and serrated polyps in the CORI dataset; however, we categorized polyps by size ( $>9 \mathrm{~mm}$ ) to determine advanced adenoma detection rates in CORI and these rates (6.2\%) were similar to the rate of advanced adenomas observed in the BMC data (6\%), confirming that polyps $>9$ $\mathrm{mm}$ in size is a valid surrogate marker.

In conclusion, our study should serve as a cautionary tale with immediately applicable clinical relevance. We found that the PDR and ADR decreased at the highest levels of bowel cleanliness, suggesting that aggressive bowel preparation regimens may not necessarily improve clinical outcomes. Endoscopists finding a pristine bowel preparation should avoid a sense of over-confidence for polyp detection during the inspection phase of screening colonoscopy and still perform a careful evaluation for polyps. Furthermore, endoscopists expending additional effort to maximize cleansing of the bowel should never sacrifice on their inspection technique or inspection time. Future research should clarify the reasons for this decrement in PDR and ADR and determine whether certain factors are modifiable in order to ensure high quality colonoscopy examinations at all levels of bowel cleanliness. 


\section{Acknowledgments}

Funding: This work was funded by NIH NIDDK, grant number K08-DK090150-03 (Calderwood). D. Lieberman and CORI are supported with funding from NIH NIDDK U01 DK057132, R33-DK61778-01, and R21-CA131626. Funding from NIDDK supports the collection, management, analysis, and interpretation of this and all CORI research. In addition, the practice network (CORI) has received support for the infrastructure of the practice-based network from AstraZeneca, Bard International, Pentax USA, ProVation, Endosoft, GIVEN Imaging, and Ethicon. The commercial entities had no involvement in this research.

\section{Acronyms}

$\begin{array}{ll}\text { ADR } & \text { adenoma detection rate } \\ \text { aOR } & \text { adjusted odds ratio } \\ \text { BBPS } & \text { Boston Bowel Preparation Scale } \\ \text { BMC } & \text { Boston Medical Center } \\ \text { BMI } & \text { body mass index } \\ \text { CI } & \text { confidence interval } \\ \text { CORI } & \text { Clinical Outcomes Research Initiative } \\ \text { DM } & \text { diabetes mellitus } \\ \text { IRB } & \text { Institutional Review Board } \\ \text { OR } & \text { odds ratio } \\ \text { PDR } & \text { polyp detection rate } \\ \text { VA } & \text { Veterans Affairs }\end{array}$

\section{References}

1. Froehlich F, Wietlisbach V, Gonvers JJ, Burnand B, Vader JP. Impact of colonic cleansing on quality and diagnostic yield of colonoscopy: the European Panel of Appropriateness of Gastrointestinal Endoscopy European multicenter study. Gastrointest Endosc. Mar; 2005 61(3): 378-384. [PubMed: 15758907]

2. Harewood GC, Sharma VK, de Garmo P. Impact of colonoscopy preparation quality on detection of suspected colonic neoplasia. Gastrointest Endosc. Jul; 2003 58(1):76-79. [PubMed: 12838225]

3. Rex DK, Imperiale TF, Latinovich DR, Bratcher LL. Impact of bowel preparation on efficiency and cost of colonoscopy. Am J Gastroenterol. Jul; 2002 97(7):1696-1700. [PubMed: 12135020]

4. Chokshi RV, Hovis CE, Hollander T, Early DS, Wang JS. Prevalence of missed adenomas in patients with inadequate bowel preparation on screening colonoscopy. Gastrointest Endosc. Jun; 2012 75(6):1197-1203. [PubMed: 22381531]

5. Lebwohl B, Kastrinos F, Glick M, Rosenbaum AJ, Wang T, Neugut AI. The impact of suboptimal bowel preparation on adenoma miss rates and the factors associated with early repeat colonoscopy. Gastrointest Endosc. Jun; 2011 73(6):1207-1214. [PubMed: 21481857]

6. Kazarian ES, Carreira FS, Toribara NW, Denberg TD. Colonoscopy completion in a large safety net health care system. Clin Gastroenterol Hepatol. Apr; 2008 6(4):438-442. [PubMed: 18304886]

7. Sherer EA, Imler TD, Imperiale TF. The effect of colonoscopy preparation quality on adenoma detection rates. Gastrointest Endosc. Mar; 2012 75(3):545-553. [PubMed: 22138085]

8. Andersen JC, Butterly LF, Robinson CM, Goodrich M, Weiss JE. Impact of fair bowel preparation quality on adenoma and serrated polyp detection: data from the New Hampshire Colonoscopy Registry by using a standardized preparation-quality rating. Gastrointest Endosc. 2014 In press. 
9. Radaelli F, Meucci G, Sgroi G, Minoli G. Technical performance of colonoscopy: the key role of sedation/analgesia and other quality indicators. Am J Gastroenterol. May; 2008 103(5):1122-1130. [PubMed: 18445096]

10. Jover R, Zapater P, Polania E, et al. Modifiable endoscopic factors that influence the adenoma detection rate in colorectal cancer screening colonoscopies. Gastrointest Endosc. Mar; 2013 77(3): 381-389. e381. [PubMed: 23218945]

11. de Jonge V, Sint Nicolaas J, Cahen DL, et al. Quality evaluation of colonoscopy reporting and colonoscopy performance in daily clinical practice. Gastrointest Endosc. Jan; 2012 75(1):98-106. [PubMed: 21907986]

12. Lai EJ, Calderwood AH, Doros G, Fix OK, Jacobson BC. The Boston bowel preparation scale: a valid and reliable instrument for colonoscopy-oriented research. Gastrointest Endosc. Mar; 2009 69(3 Suppl):620-625. [PubMed: 19136102]

13. Calderwood AH, Jacobson BC. Comprehensive validation of the Boston Bowel Preparation Scale. Gastrointest Endosc. Oct; 2011 72(4):686-692. [PubMed: 20883845]

14. Calderwood AH, Schroy PC 3rd, Lieberman DA, Logan JR, Zurfluh M, Jacobson BC. Boston Bowel Preparation Scale scores provide a standardized definition of adequate for describing bowel cleanliness. Gastrointest Endosc. Mar 12.2014 In press.

15. Lieberman DA, Holub JL, Moravec MD, Eisen GM, Peters D, Morris CD. Prevalence of colon polyps detected by colonoscopy screening in asymptomatic black and white patients. JAMA. Sep 24; 2008 300(12):1417-1422. [PubMed: 18812532]

16. Lebwohl B, Wang TC, Neugut AI. Socioeconomic and other predictors of colonoscopy preparation quality. Dig Dis Sci. Jul; 2010 55(7):2014-2020. [PubMed: 20082217]

17. Qureshi A, Ismail S, Azmi A, Murugan P, Husin M. Poor bowel preparation in patients undergoing colonoscopy. Med J Malaysia. 55:246-248. 2000/06/01 ed2000. [PubMed: 19839154]

18. Nguyen DL, Wieland M. Risk factors predictive of poor quality preparation during average risk colonoscopy screening: the importance of health literacy. J Gastrointestin Liver Dis. Dec; 2010 19(4):369-372. [PubMed: 21188326]

19. Ness RM, Manam R, Hoen H, Chalasani N. Predictors of inadequate bowel preparation for colonoscopy. Am J Gastroenterol. Jun; 2001 96(6):1797-1802. [PubMed: 11419832]

20. Burke CA. Colonic complications of obesity. Gastroenterol Clin North Am. Mar; 2010 39(1):4755. [PubMed: 20202578]

21. Borg BB, Gupta NK, Zuckerman GR, Banerjee B, Gyawali CP. Impact of obesity on bowel preparation for colonoscopy. Clin Gastroenterol Hepatol. Jun; 2009 7(6):670-675. [PubMed: 19245852]

22. Aronchick CA. Bowel preparation scale. Gastrointest Endosc. Dec; 2004 60(6):1037-1038. author reply 1038-1039. [PubMed: 15605036]

23. Tadepalli US, Feihel D, Miller KM, et al. A morphologic analysis of sessile serrated polyps observed during routine colonoscopy (with video). Gastrointest Endosc. Dec; 2011 74(6):1360 1368. [PubMed: 22018553]

24. de Wijkerslooth TR, Stoop EM, Bossuyt PM, et al. Differences in proximal serrated polyp detection among endoscopists are associated with variability in withdrawal time. Gastrointest Endosc. Apr; 2013 77(4):617-623. [PubMed: 23321338]

25. Corley DA, Jensen CD, Marks AR, et al. Adenoma detection rate and risk of colorectal cancer and death. The New England journal of medicine. Apr 3; 2014 370(14):1298-1306. [PubMed: 24693890]

26. Kaminski MF, Regula J, Kraszewska E, et al. Quality indicators for colonoscopy and the risk of interval cancer. The New England journal of medicine. May 13; 2010 362(19):1795-1803. [PubMed: 20463339]

27. Adler A, Wegscheider K, Lieberman D, et al. Factors determining the quality of screening colonoscopy: a prospective study on adenoma detection rates, from 12,134 examinations (Berlin colonoscopy project 3, BECOP-3). Gut. Feb; 2013 62(2):236-241. [PubMed: 22442161]

28. Barclay RL, Vicari JJ, Greenlaw RL. Effect of a time-dependent colonoscopic withdrawal protocol on adenoma detection during screening colonoscopy. Clinical gastroenterology and hepatology : 
the official clinical practice journal of the American Gastroenterological Association. Oct; 2008 6(10):1091-1098. [PubMed: 18639495]

29. Calderwood AH, Jacobson BC. Colonoscopy quality: metrics and implementation. Gastroenterology clinics of North America. Sep; 2013 42(3):599-618. [PubMed: 23931862]

30. Taber A, Romagnuolo J. Effect of simply recording colonoscopy withdrawal time on polyp and adenoma detection rates. Gastrointestinal endoscopy. Apr; 2010 71(4):782-786. [PubMed: 20363418]

31. Widjaja D, Bhandari M, Loveday-Laghi V, Glandt M, Balar B. Withdrawal time in excellent or very poor bowel preparation qualities. World journal of gastrointestinal endoscopy. May 16; 2014 6(5):186-192. [PubMed: 24891931] 


\section{Table 1}

Sample demographics

\begin{tabular}{|c|c|c|}
\hline & $\begin{array}{c}\text { BMC } \\
(5 / 2012-10 / 2013)\end{array}$ & $\begin{array}{c}\text { CORI } \\
(10 / 2009-5 / 2013)\end{array}$ \\
\hline $\mathrm{N}$ & 3713 & 5532 \\
\hline Female, $\%$ & 54 & 50 \\
\hline Age in yrs, median (IQR) & $55(51-62)$ & $58(52-65)$ \\
\hline $\begin{array}{l}\text { Race/ethnicity } \\
\text { Non-Hispanic white } \\
\text { Non-Hispanic black } \\
\text { Hispanic } \\
\text { Other }\end{array}$ & $\begin{array}{l}740(20.3) \\
1383(38.0) \\
877(24.1) \\
644(17.7)\end{array}$ & NA \\
\hline $\mathrm{DM}, \%$ & 12 & NA \\
\hline BMI, median (IQR) & $29(26-33)$ & NA \\
\hline $\begin{array}{l}\text { BBPS scores, n (\%) } \\
9 \\
8 \\
7 \\
6\end{array}$ & $\begin{array}{l}1444(38.9) \\
923(24.9) \\
734(20.0) \\
612(16.5)\end{array}$ & $\begin{array}{l}2376(43.0) \\
948(17.1) \\
904(16.30 \\
1304(23.6)\end{array}$ \\
\hline $\begin{array}{l}\text { Qualitative rating, n (\%) } \\
\text { Total } \\
\text { Excellent } \\
\text { Good } \\
\text { Fair } \\
\text { Poor }\end{array}$ & $\begin{array}{c}1821(49.0) \\
657(36.1) \\
1139(62.6) \\
20(1.1) \\
5(0.3)\end{array}$ & $\begin{array}{l}1060(19.2) \\
560(52.8) \\
138(13.0) \\
357(33.7) \\
5(0.5)\end{array}$ \\
\hline $\begin{array}{l}\text { Polyp detection rate, } \% \\
\quad \text { Any } \\
>9 \mathrm{~mm}\end{array}$ & $\begin{array}{l}49.8 \\
\text { NA }\end{array}$ & $\begin{array}{c}44.5 \\
6.2^{* *}\end{array}$ \\
\hline $\begin{array}{l}\text { Adenoma detection rate, \% } \\
\text { Any } \\
\text { Advanced } \\
\text { Serrated }\end{array}$ & $\begin{array}{l}37.7 \\
6.0 \\
3.6\end{array}$ & NA \\
\hline
\end{tabular}

BBPS, Boston Bowel Preparation Scale; BMC, Boston Medical Center; BMI, body mass index; CORI, Clinical Outcomes Research Initiative; DM, diabetes mellitus; IQR, interquartile range; NA, not available; yrs, years

Those with poor preparation were excluded from analysis as described in the methods

$$
* *
$$

In CORI, polyps $>9 \mathrm{~mm}$ are considered advanced adenomas 15 


\section{Table 2}

Polyp and adenoma detection rates by total Boston Bowel Preparation Scale score at Boston Medical Center (BMC) and within the Clinical Outcomes Research Initiative (CORI).

\begin{tabular}{|c|c|c|c|c|}
\hline & $\begin{array}{l}\text { Total BBPS } \\
\text { score }\end{array}$ & $\begin{array}{c}\text { Frequency, } \\
(\%)\end{array}$ & OR $(95 \% \mathrm{CI})$ & $\begin{array}{c}\text { Adjusted OR } \\
(95 \% \mathrm{CI})^{1}\end{array}$ \\
\hline \multicolumn{5}{|c|}{ Boston Medical Center } \\
\hline Polyp & $\begin{array}{l}9 \\
8 \\
7 \\
6\end{array}$ & $\begin{array}{l}663(46.0) \\
481(52.2) \\
391(53.3) \\
313(51.1)\end{array}$ & $\begin{array}{c}\text { ref } \\
1.3[1.1-1.5] \\
1.3[1.1-1.6] \\
1.2[1.0-1.5]\end{array}$ & $\begin{array}{c}\text { ref } \\
1.2[1.0-1.5] \\
1.3[1.0-1.5] \\
1.1[0.94-1.4]\end{array}$ \\
\hline Adenoma & $\begin{array}{l}9 \\
8 \\
7 \\
6\end{array}$ & $\begin{array}{l}490(34.3) \\
354(38.8) \\
295(40.6) \\
243(40.4)\end{array}$ & $\begin{array}{c}\text { ref } \\
1.2[1.0-1.4] \\
1.3[1.1-1.6] \\
1.3[1.1-1.6]\end{array}$ & $\begin{array}{c}\text { ref } \\
1.1[0.96-1.4] \\
1.2[1.0-1.5] \\
1.2[0.99-1.5]\end{array}$ \\
\hline $\begin{array}{c}\text { Advanced } \\
\text { adenoma }\end{array}$ & $\begin{array}{l}9 \\
8 \\
7 \\
6\end{array}$ & $\begin{array}{l}59(4.1) \\
60(6.5) \\
55(7.5) \\
46(7.6)\end{array}$ & $\begin{array}{c}\text { ref } \\
1.6[1.1-2.4] \\
1.9[1.3-2.8] \\
1.9[1.3-2.9]\end{array}$ & $\begin{array}{c}\mathrm{ref} \\
1.6[1.1-2.3] \\
1.7[1.1-2.5] \\
1.8[1.2-2.7]\end{array}$ \\
\hline \multicolumn{5}{|c|}{ Clinical Outcomes Research Initiative } \\
\hline Polyp & $\begin{array}{l}9 \\
8 \\
7 \\
6\end{array}$ & $\begin{array}{l}943(39.7) \\
424(44.7) \\
433(47.9) \\
664(50.9)\end{array}$ & $\begin{array}{c}\text { ref } \\
1.2[1.1-1.4] \\
1.4[1.2-1.6] \\
1.6[1.4-1.8]\end{array}$ & $\begin{array}{c}\text { ref } \\
1.2[1.0-1.4] \\
1.4[1.2-1.6] \\
1.5[1.3-1.7]\end{array}$ \\
\hline Polyp $>9 \mathrm{~mm}$ & $\begin{array}{l}9 \\
8 \\
7 \\
6\end{array}$ & $\begin{array}{c}131(5.5) \\
48(5.1) \\
44(4.9) \\
117(9.0)\end{array}$ & $\begin{array}{c}\text { ref } \\
0.91[0.65-1.3] \\
0.88[0.62-1.2] \\
1.7[1.3-2.2]\end{array}$ & $\begin{array}{c}\text { ref } \\
0.88[0.63-1.2] \\
0.85[0.60-1.2] \\
1.6[1.2-2.0]\end{array}$ \\
\hline
\end{tabular}

BBPS, Boston Bowel Preparation; CI, confidence interval; OR, odds ratio; ref, reference

${ }^{1}$ Adjusted for age, gender, and race/ethnicity in BMC data; adjusted for age, gender in CORI (race/ethnicity not available) 


\section{Table 3}

Polyp and adenoma detection rates by qualitative assessment of bowel cleanliness at Boston Medical Center (BMC) and within the Clinical Outcomes Research Initiative (CORI).

\begin{tabular}{|c|c|c|c|c|}
\hline & $\begin{array}{c}\text { Qualitative } \\
\text { score }\end{array}$ & $\begin{array}{l}\text { Frequency, } \\
\text { n (\%) }\end{array}$ & OR $(95 \% \mathrm{CI})$ & $\begin{array}{c}\text { Adjusted OR } \\
(95 \% \text { CI })\end{array}$ \\
\hline \multicolumn{5}{|c|}{ Boston Medical Center } \\
\hline Polyp & $\begin{array}{l}\text { Excellent } \\
\text { Good }\end{array}$ & $\begin{array}{l}318(48.5) \\
618(54.3)\end{array}$ & $\begin{array}{c}\text { ref } \\
1.3[1.0-1.5]\end{array}$ & $\begin{array}{c}\operatorname{ref} \\
1.1[0.94-1.4]\end{array}$ \\
\hline Adenoma & $\begin{array}{l}\text { Excellent } \\
\text { Good }\end{array}$ & $\begin{array}{l}242(37.2) \\
484(43.3)\end{array}$ & $\begin{array}{c}\text { ref } \\
1.3[1.1-1.6]\end{array}$ & $\begin{array}{c}\operatorname{ref} \\
1.2[0.94-1.4]\end{array}$ \\
\hline $\begin{array}{c}\text { Advanced } \\
\text { adenoma }\end{array}$ & $\begin{array}{l}\text { Excellent } \\
\text { Good }\end{array}$ & $\begin{array}{l}31(4.7) \\
76(6.7)\end{array}$ & $\begin{array}{c}\text { ref } \\
1.4[0.94-2.2]\end{array}$ & $\begin{array}{c}\text { ref } \\
1.3[0.83-2.0]\end{array}$ \\
\hline \multicolumn{5}{|c|}{ Clinical Outcomes Research Initiative } \\
\hline Polyp & $\begin{array}{c}\text { Excellent } \\
\text { Good } \\
\text { Fair }\end{array}$ & $\begin{array}{l}206(36.8) \\
101(73.2) \\
191(53.5)\end{array}$ & $\begin{array}{c}\text { ref } \\
4.7[3.1-7.1] \\
2.0[1.5-2.6]\end{array}$ & $\begin{array}{c}\text { ref } \\
1.4[2.2-5.2] \\
1.9[1.4-2.4]\end{array}$ \\
\hline Polyp $>9 \mathrm{~mm}$ & $\begin{array}{l}\text { Excellent } \\
\text { Good } \\
\text { Fair }\end{array}$ & $\begin{array}{c}18(3.2) \\
21(15.2) \\
22(6.2)\end{array}$ & $\begin{array}{c}\text { ref } \\
5.4[2.8-10.5] \\
2.0[1.0-3.7]\end{array}$ & $\begin{array}{c}\mathrm{ref} \\
3.8[1.9-7.6] \\
1.8[0.94-3.4]\end{array}$ \\
\hline
\end{tabular}

CI, confidence interval; OR, odds ratio; ref, reference

${ }^{1}$ Adjusted for age, gender, and race/ethnicity in BMC data; adjusted for age, gender in CORI (race/ethnicity not available). 
Table 4

Polyp and adenoma detection rates by segment BBPS score at Boston Medical Center (BMC) and within the Clinical Outcomes Research Initiative (CORI).

\begin{tabular}{|c|c|c|c|c|}
\hline & $\begin{array}{c}\text { Segment } \\
\text { BBPS score }\end{array}$ & $\begin{array}{l}\text { Frequency, } \\
\quad \text { ( }(\%)\end{array}$ & OR $(95 \% \mathrm{CI})$ & $\begin{array}{c}\text { Adjusted OR } \\
(95 \% \mathrm{CI})^{1}\end{array}$ \\
\hline \multicolumn{5}{|c|}{ Boston Medical Center } \\
\hline Polyp & $\begin{array}{l}3 \\
2\end{array}$ & $\begin{array}{l}1551(22.4) \\
1000(23.9)\end{array}$ & $\begin{array}{c}\mathrm{ref} \\
1.1[0.99-1.2]\end{array}$ & $\begin{array}{c}\operatorname{ref} \\
1.0[0.94-1.1]\end{array}$ \\
\hline Adenoma & $\begin{array}{l}3 \\
2\end{array}$ & $\begin{array}{c}1064(15.5) \\
757(18.2)\end{array}$ & $\begin{array}{c}\text { ref } \\
1.2[1.1-1.3]\end{array}$ & $\begin{array}{c}\text { ref } \\
1.2[1.0-1.3]\end{array}$ \\
\hline $\begin{array}{c}\text { Advanced } \\
\text { adenoma }\end{array}$ & $\begin{array}{l}3 \\
2\end{array}$ & $\begin{array}{l}140(2.0) \\
104(2.5)\end{array}$ & $\begin{array}{c}\text { ref } \\
1.2[0.96-1.6]\end{array}$ & $\begin{array}{c}\text { ref } \\
1.2[0.92-1.6]\end{array}$ \\
\hline \multicolumn{5}{|c|}{ Clinical Outcomes Research Initiative } \\
\hline Polyp & $\begin{array}{l}3 \\
2\end{array}$ & $\begin{array}{l}1817(18.3) \\
1370(21.2)\end{array}$ & $\begin{array}{c}\text { ref } \\
1.2[1.1-1.3]\end{array}$ & $\begin{array}{c}\text { ref } \\
1.2[1.1-1.2]\end{array}$ \\
\hline Polyp $>9 \mathrm{~mm}$ & $\begin{array}{l}3 \\
2\end{array}$ & $\begin{array}{l}201(2.0) \\
164(2.5)\end{array}$ & $\begin{array}{c}\text { ref } \\
1.3[1.0-1.6]\end{array}$ & $\begin{array}{c}\mathrm{ref} \\
1.2[0.97-1.5]\end{array}$ \\
\hline
\end{tabular}

BBPS, Boston Bowel Preparation; CI, confidence interval; OR, odds ratio; ref, reference

${ }^{1}$ Adjusted for age, gender, and race/ethnicity in BMC data; adjusted for age, gender in CORI (race/ethnicity not available). 


\section{Appendix 1}

Evaluation of the association between potential covariates and bowel cleanliness and presence of polyps and adenomas at Boston Medical Center (a) and within the Clinical Outcomes Research Initiative (b).

\section{(a) Boston Medical Center}

\begin{tabular}{|c|c|c|c|}
\hline \multirow[b]{2}{*}{ Variable } & \multicolumn{3}{|c|}{ OR $[95 \% \mathrm{CI}]$} \\
\hline & $\begin{array}{c}\text { Bowel cleanliness } \\
\text { (BBPS) }\end{array}$ & Polyps & Adenomas \\
\hline Age & $0.99[0.98-1.0]$ & $1.02[1.01-1.03]$ & $1.03[1.02-1.04$ \\
\hline Gender $(\mathrm{ref}=\mathrm{male})$ & $1.4[1.2-1.5]$ & $0.57[0.50-0.65]$ & $0.61[0.54-0.70$ \\
\hline $\begin{array}{l}\text { Race/ethnicity } \\
\text { (ref=Non-Hispanic white) } \\
\text { Non-Hispanic black } \\
\text { Hispanic } \\
\text { Other }\end{array}$ & $\begin{array}{l}0.73[0.61-0.87] \\
0.71[0.58-0.87] \\
0.69[0.56-0.86]\end{array}$ & $\begin{array}{l}0.68[0.57-0.81] \\
0.63[0.52-0.77] \\
0.62[0.50-0.76]\end{array}$ & $\begin{array}{l}0.70[0.59-0.85 \\
0.69[0.56-0.84 \\
0.70[0.57-0.83\end{array}$ \\
\hline DM & $0.50[0.49-0.70]$ & 1.2 [0.98-1.4] & $1.2[1.0-1.5]$ \\
\hline BMI & $1.0[1.0-1.0]$ & $1.0[1.0-1.0]$ & $1.0[1.0-1.0]$ \\
\hline
\end{tabular}

(b) Clinical Outcomes Research Initiative

\begin{tabular}{|l|c|c|}
\hline & \multicolumn{2}{|c|}{ OR [95\% CI] } \\
\hline \multicolumn{1}{|c|}{ Variable } & $\begin{array}{c}\text { Bowel cleanliness } \\
\text { (BBPS) }\end{array}$ & Polyps \\
\hline Age & $0.99[0.98-0.99]$ & $1.01[1.01-1.03]$ \\
\hline Gender (ref=male) & $1.4[1.3-1.5]$ & $0.51[0.46-0.56]$ \\
\hline
\end{tabular}

BBPS, Boston Bowel Preparation; BMI, body mass index; CI, confidence interval; DM, diabetes mellitus; OR, odds ratio; ref, reference 